\title{
Schmidentity and informativity
}

\author{
Hannes Fraissler ${ }^{1}$
}

Received: 1 July 2019 / Accepted: 12 May 2020 / Published online: 3 September 2020

(c) The Author(s) 2020, corrected publication 2020

\begin{abstract}
Although Kripke's œuvre has had a major impact on analytic philosophy and nearly every aspect of his studies has been thoroughly examined, this does not hold for his schmidentity argument, which, so far, has been widely neglected. ${ }^{\mathrm{i}}$ To the extent to which it has been treated at all, it has been for the most part radically misunderstood. I hold that this argument, in its correctly reconstructed form, has general relevance for a treatment of Frege's Puzzle $e^{\mathrm{ii}}$ and points towards a fundamental methodological restriction for philosophy of language and especially for semantics, as far as informativity and the general topic of cognitive significance are concerned. To show this, I will (Sect. 1) briefly set out the context of the schmidentity argument and, in Sects. 2 and 4, sketch a reconstruction thereof, including (Sect. 3) some criticisms of the argument, and (Sect. 6) an excursion about Kit Fine's semantic relationism, which stands in stark contrast to this paper's central claim. ${ }^{\text {iii }}$ Moreover, I will (Sect. 5) draw a genuinely new and probably quite unexpected conclusion from all the above (amounting to the position that Frege's Puzzle cannot be solved in terms of semantics), to finally (Sect. 7) give a glimpse at a bigger picture of where this conclusion should lead our thinking about a theoretical treatment of informativity and a linguistic expression's cognitive value.
\end{abstract}

Keywords Frege's Puzzle · Identity sentences/statements · Kripke ·

Informativeness/cognitive significance $\cdot$ Millianism $\cdot$ Semantic relationism

A shorter precursor of this paper (which originated from chap. 4 of my 2014) was held as a contributed section talk at the GAP.9 conference in Osnabrück (Germany) in Sept. 2015.

$凶 \quad$ Hannes Fraissler

hannes.fraissler@gmail.com

1 Institute of Philosophy, Université du Luxembourg, Maison des Sciences Humaines, 11, Porte des Sciences, Esch-sur-Alzette 4366, Luxembourg 


\section{Notes}

i The schmidentity argument was influential at least insofar as it launched a kind of fashion to use a language phenomenon called shm-reduplication in philosophical discussion. (For a telling and easily accessible example, see Deutsch and Garbacz 2018 , § 3.) Although Kripke had precursors in this respect (e.g. Ullian 1961, p. 387), the habit of using shm-reduplications, which many notable philosophers adopted, is most plausibly traced back to the relevant passage in Kripke (1980, p. 108). For a linguistic investigation of shm-reduplication, including information about its origin and meaning, see Nevins and Vaux (2003). For a brief discussion of how far the general principles of shm-reduplication are applicable to the schmidentity argument, and a selection of shm-reduplication examples in philosophy, see Fraissler (2014, pp. $88 \mathrm{f})$.

ii Throughout this paper, I am exclusively concerned with questions regarding identity sentences or statements of identity when I talk about Frege's Puzzle. Corresponding questions of belief ascription-which often also come under the label "Frege's Puzzle"- are not treated in this text.

iii Readers who are unfamiliar with, or not interested in, Fine's theory might also skip Sect. 6, which is concerned with semantic relationism and its relevance for the matters in question.

\section{Introduction}

At the beginning of the $3^{\text {rd }}$ lecture of Naming and Necessity, Saul Kripke uses the schmidentity argument to defend his preferred analysis of identity sentences as expressing mere self-identity (call this the objectual account) against a competing theory, namely the metalinguistic account. According to the objectual account, what identity sentences express is that a certain relation, namely identity, holds; where identity is a relation that every object bears to itself but to no other object. According to the metalinguistic account, identity sentences do not express (the holding of) the identity relation, but the relation of co-reference instead, i.e. a relation between linguistic expressions. Frege reports that he endorsed the metalinguistic view to make sense of what identity sentences mean in his Begriffsschrift, before he developed his famous theory of sense and reference (cf. Frege 1960, p. 56). ${ }^{1}$

The ultimate motivation to endorse the metalinguistic theory surely is its straightforward way to solve Frege's Puzzle and the related issue of informativity: If identity sentences really are about the identified objects, and names have no other semantic function than picking out their referents, then it is hard to see how "Cicero is Tully" could be more informative than "Cicero is Cicero," because the two sentences have exactly the same meaning; given of course that Cicero is in fact Tully. The metalinguistic view seems to neatly account for the difference in cognitive significance ${ }^{2}$ between

\footnotetext{
1 For arguments that the metalinguistic account is inconsistent with Frege's Begriffsschrift project, cf. White (1978, pp. 157-9), Williams (1989, pp. 22 f), and Caton (1976, pp. 174f). Regarding Frege's mature theory, which distinguishes between sense and reference, see the first paragraph of Sect. 5.

${ }^{2}$ I will not differentiate between cognitive significance and cognitive value in this paper.
} 
"Cicero is Cicero" and "Cicero is Tully": According to the metalinguistic view, the first sentence means " Cicero' co-refers with/picks out the same as 'Cicero"” and the second says that "Cicero' co-refers with/picks out the same as 'Tully"'. While the first sentence talks about the same name twice, the second sentence talks about two different names and informs us that they refer to the same thing. The two sentences have of course very different meanings, because they do not talk about the same things (the second sentence talks about a name which does not appear in the first sentence at all) and the different meanings are then supposed to explain the difference in cognitive value.

Kripke's schmidentity argument was designed to defend the objectual view (originally only) against the metalinguistic account. It runs as follows:

If anyone ever inclines to this particular [metalinguistic] account of identity, let's suppose we gave him his account. Suppose identity were a relation in English between the names. I shall introduce an artificial relation called "schmidentity" (not a word of English) which I now stipulate to hold only between an object and itself. [Footnote omitted] Now then the question whether Cicero is schmidentical with Tully can arise, and if it does arise the same problems will hold for this statement as were thought in the case of the original identity statement to give the belief that this was a relation between the names. If anyone thinks about this seriously, I think he will see that therefore probably his original [i.e. metalinguistic] account of identity was not necessary, and probably not possible, for the problems it was originally meant to solve, and that therefore it should be dropped, and identity should just be taken to be the relation between a thing and itself. This sort of device can be used for a number of philosophical problems. (Kripke 1980, p. 108)

Kripke's formulation might wrongly suggest that the nature of identity itself was at stake, rather than what identity sentences mean. But I suppose that even a metalinguist would agree that an identity sentence, such as "Cicero is (identical with) Tully," is true iff the referent of "Cicero" is the same as, viz. is identical with, the referent of "Tully". I therefore assume that there is no disagreement about the nature of the identity relation between the objectual and the metalinguistic views. ${ }^{3}$ The disagreement concerns the meaning of identity sentences. Do they express that the co-reference relation holds between certain expressions, as the metalinguistic account claims, or do identity sentences express that the referents of the expressions involved are the same, as the objectual account has it? The schmidentity argument is concerned with semantic questions, not with the metaphysics of identity. We can paraphrase Kripke's argument to avoid this possible confusion.

If somebody inclines to accept the metalinguistic theory because of its ability to account for the informativity challenge, then consider the following: We leave this account to the metalinguist and presume that identity sentences express

\footnotetext{
3 This might not hold true for Ludwig Wittgenstein's treatment of identity, which is also sometimes called "metalinguistic" (cf. Muehlmann 1969, p. 228). Wittgenstein's account is, however, probably best understood as a non-relational analysis of identity (cf. Williams 1989, p. 21). This disqualifies Wittgenstein as a metalinguist in the relevant sense because co-reference, which lies at the heart of the metalinguistic view, clearly is a relation.
} 
the co-reference of words, not the identity of objects. We then stipulatively introduce a relation called "schmidentity," which is to hold only between an object and itself. A schmidentity sentence therefore merely expresses that the relation of identity holds, but co-reference is not part of its meaning. Now we have to ask whether a sentence like "Hesperus is schmidentical with Phosphorus" would not be just as informative as "Hesperus is identical with Phosphorus." This consideration should lead to the conclusion that the metalinguistic account is not able to solve the problem because informativeness ${ }^{4}$ simply reappears as a feature of schmidentity sentences, and the metalinguistic theory per definitionem cannot explain the phenomenon of informativity in connection with schmidentity sentences. Consequently, the metalinguistic account should be rejected as a theory about informative identity sentences.

On the basis of this all too brief presentation, it is hardly possible to recognize the structure and underlying strategy of the argument. A more elaborate reconstruction is needed to unveil its strength and virtues.

\section{Reconstruction (Part I)}

By far the most convincing reconstruction of the schmidentity argument is due to Murali Ramachandran (cf. Ramachandran 1989; and esp. Ramachandran 1995), who identifies two distinct principles governing the argumentation and organizing it into two thrusts. The first of these principles, the Counterexample Principle (cf. Ramachandran 1995, p. 68), which is at the heart of the so-called Schmidentity Defense (cf. Ramachandran 1995, pp. $73 \mathrm{ff}$ ), is also explicitly stated by Kripke himself.

Counterexample Principle If a linguistic phenomenon is taken to refute a given language analysis, then we should observe whether this very phenomenon could occur in a (hypothetical) language, which is stipulatively governed by the analysis in question. If the phenomenon could occur in this (hypothetical) language, then its occurrence in real language cannot disprove that the analysis is correct for the actually spoken language. (Cf. Kripke 2011d, p. 113; and Kripke 2013, pp. $114 \mathrm{f}.)^{5}$

Kripke famously uses this principle to argue that Donnellan's distinction between referential and attributive uses of definite descriptions by no means tells against Russell's

\footnotetext{
${ }^{4}$ I use "informativeness" and "informativity" interchangeably throughout this paper.

${ }^{5}$ Kripke, in his formulation of the principle, demands that the linguistic phenomenon not only could but actually would occur in the stipulated (hypothetical) language. To circumvent certain objections turning on this "would" (cf. Devitt 1981, p. 520; Devitt 2004, p. 287) the principle can simply be changed in this respect and still remains strong enough to carry the conclusion. (Cf. Ramachandran 1995, pp. 69f.) Devitt's complaints definitely call for extended discussion, but I will refrain from addressing his arguments in detail at this point. Although his latter text adds a considerable complication to a satisfying answer to his criticism (namely that the phenomenon to be accounted for is not merely possible or actual, but regular occurrence of referentially used definite descriptions), I think that, in the end, the aforementioned change of the Counterexample Principle settles the most pressing issues pointed out by Devitt against Kripke's argument.
} 
theory of definite descriptions. If we take Donnellan to claim that the existence of referentially used descriptions renders Russell's analysis incorrect or at least incomplete, because Russell's theory can only (if at all) handle attributively used definite descriptions, then we should reevaluate the validity of this claim by using Kripke's "device of imagining a hypothetical language" (Kripke 1980, p. 108n).

Imagine a community speaking a language (call it Russell English) which resembles the actually spoken language as closely as possible and where Russell's analysis of definite descriptions is stipulated to be true. ${ }^{6}$ When we now ask if people in that imagined community could use definite descriptions referentially then we can see that it could in fact happen, simply because the members of the Russell English community are not infallible. A Russell English speaker may want to pick out something by calling it "the so and so" to say that it is thus and that and even be successful in communicating to other Russell English speakers that the thing he means is thus and that although it is not the so and so. The Russell English speaker thus conveys what he wants to inform the others about although what he literally says by uttering "The so and so is thus and that" is not true in Russell English because the real so and so, i.e. the one and only thing satisfying the criterion of being so and so, is not thus and that - or might not even exist at all. In spite of all this, our Russell English speaker fulfills all requirements for using a definite description referentially, ${ }^{7}$ although he might not be aware of this. Moreover, he does not even intend to do so and would probably withdraw his original statement when he came to know the facts, since he is interested in using his language correctly and would, like all of his language community fellows in possession of the relevant information, agree that the sentence he uttered is false. If the phenomenon of referentially used definite descriptions could even occur in Russell English, which is stipulatively governed by Russell's theory of definite descriptions, then the actual occurrence of referentially used definite descriptions certainly cannot falsify Russell's analysis. The same point put differently: If speakers of Russell English could use definite descriptions referentially then the fact that we use definite descriptions referentially cannot show that we do not speak Russell English. ${ }^{8}$

Applied against the metalinguistic account, this means that because the informativity phenomenon would (or at least could) even occur in Schmenglish, ${ }^{9}$ the actual occurrence of informative identity sentences in English cannot falsify the objectual account.

\footnotetext{
6 This means that the language is governed by Russell's semantics for definite descriptions such that every utterance of a definite description in this language is equivalent with or simply abbreviates the explicitly quantified expression. (For general—but for our purposes, I think, ultimately unconvincing—reservations against this kind of stipulation see Millican and Over 1990, pp. 173f.)

7 Namely using "the description to enable his audience to pick out whom or what he is talking about and stating something about that person or thing." (Donnellan 1966, p. 285)

8 Or at least a language that is governed by the same principles as Russell English-except for the fact that we of course do not speak a language that stipulatively follows Russell's analysis. The actual language could only de facto be in accordance with Russell's theory of definite descriptions.

${ }^{9}$ In this imagined, hypothetical language, schmidentity sentences (which are in accordance with the stipulatively introduced relation called "schmidentity") are uttered instead of identity sentences. So, the objectual account is (stipulatively) true for Schmenglish and schmidentity sentences merely express the schmidentity (i.e. self-identity) of objects. Still, self-identity can be distinguished from schmidentity; see n. 14 in Sect. 3.
} 
We should stop here for a moment, since this already represents a highly relevant result with far-reaching consequences. The actual appearance of informative identity sentences - or, in other words, the cognitive difference between sentences of the form $\ulcorner a=a\urcorner$ and $\ulcorner a=b\urcorner$-is still often cited as the most important and decisive objection against the objectual account. ${ }^{10}$ But if the following Schmidentity Defense succeeds, this would prove that Frege's Puzzle is no problem for Millian-Russellian views at all. ${ }^{11}$ Put differently, a successful schmidentity argument refutes the conceived view about Frege's Puzzle. We should therefore not teach students anymore that Frege's Puzzle is a threatening objection against Millianism, since if the result from the Schmidentity Defense is correct, this standard argument against the objectual account turns out to be a non-starter, and thus the discussion of this topic (i.e. Frege's Puzzle) cannot be led further on the same way as it usually was up until now. I strongly agree with Nathan Salmon that "Frege's Puzzle by itself is certainly not the final and conclusive refutation of [Millianism] that the orthodox theorists have taken it to be." (Salmon 1986, p. 79) And, I should add, the schmidentity argument-more precisely the Schmidentity Defense with its Counterexample Principle-proves this. Consequentially, the schmidentity argument must be considered a real game changer in this respect. Ramachandran reconstructs the argument as follows:

- Schmidentity Defense -

(D1) English identity sentences can be informative. (The claim to be rebutted is that this phenomenon disproves the objectual account of identity.)

(D2) Let Schmenglish be a language which (as much as possible) is like English except that the objectual account is stipulated to be correct. (Thus, in Schmenglish, identity [i.e. schmidentity] sentences express the schmidentity of objects.)

(D3) Some identity [i.e. schmidentity] sentences would still be informative in a community which spoke Schmenglish.

(D4) Hence, by the Counterexample Principle, the fact that English identity sentences are informative does not disprove the hypothesis that the objectual account of identity is correct for English.

(Ramachandran 1995, p. 73)

Remember that the Counterexample Principle says that if a linguistic phenomenon, which is supposed to disprove a certain theory about a certain language, could occur in a hypothetical language which is stipulatively governed by the theory in question, then the phenomenon has to be dismissed as a counterexample to the theory.

\footnotetext{
${ }^{10}$ For a rather recent example of this practice, cf. Haze (2016, p. 273). Also Jeff Speaks mentions Frege's Puzzle as the "[p]erhaps [...] most important problem facing Millian-Russellian views" (Speaks 2018, $\S$ 2.1.6) and "the neat solution [Fregean semantics] offers to Frege's puzzle" (Speaks 2018, § 2.1.7) in his SEP article about 'Theories of Meaning'. He therewith, beyond any doubt, correctly reports on the conceived view about the matters in question. To name one last example, Colin McGinn repeatedly suggests that "the really troublesome issues that arise if we accept Kripke's theory are the problems about the sense of names, raised by Frege" (McGinn 2015, p. 49) in his otherwise mostly excellent introduction to Philosophy of Language.

11 And if the Schmidentity Attack (see Sects. 4 and 5) prevails as well, this would mean that Fregean semantics cannot even solve Frege's Puzzle.
} 


\section{Criticisms}

At least some authors have discussed the schmidentity argument ${ }^{12}$ and usually rejected it. ${ }^{13}$ The most common reaction has been to attack the third premise, (D3), which says that there could be informative identity (or schmidentity) sentences or statements in Schmenglish. I will interpret these authors as holding that the argument is in fact valid but unsound because of premise (D3). The reason for rejecting this premise seems to be quite straightforward: Kripke defined the relation "...is schmidentical with..." as to hold only between an object and itself. So, saying that some $x$ is schmidentical with some $y$ boils down to saying that this $x$ (which is $y$ ) is self-identical; and this of course must be trivial. ${ }^{14}$ This in turn is exactly the same situation we started with in the beginning by stating Frege's Puzzle. Indeed, the objection against Kripke's argument is that he did not show but merely presupposed that there can be informative schmidentity sentences; and if he could show that there can be informative schmidentity sentences, the whole schmidentity argument would be superfluous, because he could have explained away Frege's Puzzle from the outset. (Cf. Benfield and Erwin 1975, pp. 146f.)

This way of reasoning might seem appealing if one regards Kripke's argument as a mere deductive argument; but this is not how Kripke himself set up the schmidentity argument. He describes it as a thought experiment (cf. Kripke 1980, p. 14) and the alleged gap in Kripke's argument (i.e. the missing demonstration that there in fact could be informative schmidentity sentences) is closed if one takes into account the argument's thought-experiment-like character. Kripke asks us to imagine a hypothetical community of speakers who speak Schmenglish. This means that every speaker in this community is wholly aware of and accepts the definition of the schmidentity relation. ${ }^{15}$ But in every other respect the speakers of Schmenglish are as much as possible like us. This means that they are of course neither infallible nor omniscient. Kripke then asks us about our intuitions of what speakers of Schmenglish might experience

\footnotetext{
12 Esp. Benfield and Erwin (1975), Morris (1984, pp. 50-53), Williams (1989, pp. 80-82), Ramachandran (1989, 1995), and Petersen (2008). The list can be kept quite short because most often the schmidentity argument is only very briefly described or merely mentioned, but not examined in a noteworthy way.

13 One prominent exception is Nathan Salmon, who calls it a useful and powerful form of argument (cf. Salmon 1989, pp. 215f; and Salmon 2005, pp. 23f). But not all of Salmon's own attempts to reproduce a schmidentity-like argument seem to be entirely successful, which indicates that even proponents of the schmidentity argument did not fully grasp its structure and functioning.

14 In order to prevent a possible misconception at this point, we should explicitly state that although schmidentity is closely related to self-identity, this does not make schmidentity a one-place relation (i.e. a property) like self-identity, since there still has to be room for misapplication of the schmidentity relation. This possibility does not even seem to exist for self-identity. So, schmidentity and self-identity probably are different relations/properties, albeit they are firmly connected. (Or maybe schmidentity and self-identity are actually the same, and the apparent difference merely concerns the respective predicates. For present purposes, however, we do not need to settle the question whether schmidentity and self-identity differ ontologically or only linguistically.) I wish to thank Oliver Motz for bringing this point to my attention.

15 We can spell this description of the situation out by saying that there exists an institution, similar to the Académie française, which represents the undisputed authority for all issues related to the Schmenglish language. This Académie schmenglaise, we might call it, established the precise meaning of "schmidentical" many generations ago and this fixation is ever since taught to all pupils in every school of the Schmenglish language community.
} 
and say when they encounter the sentence "Hesperus is schmidentical with Phosphorus." 16 This sentence is just as informative for a speaker of Schmenglish as "Hesperus is Phosphorus" appears to be informative to us. This reasoning should validate premise (D3) if intuitions about hypothetical languages can be trusted at all. Since Kripke's argument essentially includes this thought experiment, his claim that there in fact are (or at least could be) informative schmidentity sentences cannot be dismissed as a mere presupposition. Also, the demonstration that schmidentity sentences can be informative does not render the schmidentity argument superfluous, because it unpacks the consequences of this insight, using specifically linguistic principles, in a non-trivial manner.

Thus far the worries expressed in Benfield and Erwin (1975) are countered, since the authors faulted (1) that Kripke did not give any reason to believe that schmidentity sentences could be informative and (2) that if he had done so, this would render the introduction of schmidentity superfluous. We saw that exactly by introducing the schmidentity relation and imagining the situation in a Schmenglish speaker community, Kripke provides intuitive evidence for his claim that schmidentity sentences would/could be informative. So, it seems that Benfield and Erwin simply did not realize that the schmidentity argument essentially includes a thought experiment. Since Benfield and Erwin (1975) does not comprise any independent argument to validate their claim that Kripke did not establish the informativity of schmidentity sentences, no more than pointing out the schmidentity argument's thought-experiment-like character is needed to reject their criticism.

It is obvious that Benfield and Erwin did not regard the introduction of a hypothetical language and the imagination or "mental simulation" of the members' (linguistically relevant) behavior in this language community as a necessary step of the schmidentity argument. They did very well note the appearance of a thought experiment in the argument against the metalinguistic theory as well as in the discussion of Russell's theory of definite descriptions, but Benfield and Erwin (1975) simply shrugs off this feature as a useless embellishment. Nevertheless, it should be noted that the passage which explicitly reveals the schmidentity argument as a thought experiment in the preface of Naming and Necessity (cf. Kripke 1980, p. 14) was not available at the time when Benfield and Erwin (1975) was written. Anyhow, their analysis might include another shortcoming: Benfield and Erwin probably misjudged the schmidentity argument's range of applicability, since they tried to illustrate its basic rationale by means of an example involving a fuse and broken lights. This reconstruction of the argument's structure might have led them astray in assuming that the purpose of the schmidentity argument is nothing more than simply to provide a counter example to any old "hostile" modus tollens. The foregoing reconstruction of the schmidentity argument should (and this will become even clearer in the remainder of this paper) so far at least have revealed (1) that the functioning and structure of the schmidentity argument is in fact considerably more complicated than just some mechanism to provide a counter example and (2) that the schmidentity argument is a specialized tool to exclusively

\footnotetext{
16 This sentence is stated in our language and expresses only that the schmidentity relation holds in regard to Venus. In Schmenglish, of course, the corresponding statement would sound like "Hesperus is identical with Phosphorus." But this is, in accordance with the presumption that "identical" is to denote the co-reference relation for the present discussion, not how we utter the sentence.
} 
evaluate linguistic hypotheses and semantic questions. This is the field of the schmidentity argument's utility, but it is completely useless in matters of fuses and light switches or other nonlinguistic areas.

There are two other noteworthy critics of the schmidentity argument who did a better job because they do not simply assert that Kripke failed to establish premise (D3), like Benfield and Erwin (1975), but try to also explain why Kripke failed in doing so. The first attempt to argue for Kripke's failure in this respect is to be found in Morris (1984). He asks if it is really true that, as Kripke claims, e.g. the questions whether Cicero is schmidentical with Tully or Hesperus is schmidentical with Phosphorus can arise. If they cannot arise, schmidentity sentences cannot be informative; and so, Morris also attacks premise (D3). He argues that e.g. the question whether Hesperus and Phosphorus are schmidentical cannot arise because according to the stipulated definition of the schmidentity relation, as the smallest reflexive relation which everything bears to itself but to no other object (cf. Kripke 1980, p. 108), it cannot even possibly arise. Regarding the question whether Hesperus is schmidentical with Phosphorus, there are only two possible scenarios: Either Hesperus and Phosphorus are one and the same object or they are two different objects. If Hesperus and Phosphorus are two different objects, then the question whether Hesperus and Phosphorus are schmidentical cannot arise. The definition of the schmidentity relation precludes that an object stands in the relation of schmidentity to any object but itself. In the second case we suppose that Hesperus and Phosphorus are one and the same object. Since, by definition, every object bears the schmidentity relation to itself, no question as to whether any particular object bears this relation to itself can possibly arise. So, Morris concludes, in no possible scenario could the question whether Hesperus is schmidentical with Phosphorus, or any other question of schmidentity, ever arise. Therefore, there cannot be informative schmidentity sentences. (Cf. Morris 1984, pp. 52f.)

From the very definition of schmidentity it follows ${ }^{17}$ that whenever the relation of schmidentity holds, it does so necessarily; and whenever it fails to hold, it also does so necessarily. Morris seems to conclude from this fact that the question whether the schmidentity relation holds in any particular case cannot even arise. Given that the notions of necessity and apriority do not coincide in their respective extension (as Kripke prominently demonstrated), it cannot be argued that because something is necessary, ${ }^{18}$ the question as to whether it is the case or not cannot arise. If one accepts Kripke's framework, it is necessary that Hesperus is Phosphorus, that water is $\mathrm{H}_{2} \mathrm{O}$, and that whales are mammals, although these matters can only be settled empirically. Hence, the respective questions surely can arise. But even if one is not willing to accept Kripke's result that the notions of necessity and apriority come apart in their extensions, Morris' conclusion does not hold true. Take any non-trivial mathematical proposition (which can reasonably be said to be necessary, as well as a priori-just like all mathematical propositions probably are), such as Goldbach's conjecture. Still,

\footnotetext{
17 At least if we take into account Kripke's (or rather Ruth Barcan Marcus' and Willard Van Orman Quine's; cf. Burgess 2014) findings in regard to the necessity of identity. (Cf. Kripke 2011a.)

18 In some authors' works "necessary" is meant to stand for "necessarily true" or "obtaining necessarily" etc. I, however, will consistently use the term "necessary" interchangeably with "not contingent". Therefore, when something is called "necessary" here, it is either necessarily true or necessarily false, either obtaining necessarily or necessarily not obtaining, etc.
} 
the question whether Goldbach's conjecture holds, does of course arise. So, Morris' transition from something being necessary to the conclusion that a particular question cannot arise is unwarranted.

The last attack against the schmidentity argument I want to consider here comes from Christopher Williams. He takes his response to Kripke to be fairly similar to Morris', but it is still quite differently_and in my opinion much more vigorouslyformulated. Williams says:

If schmidentity is really a relation between objects, the question whether Cicero is schmidentical with Tully is schmidentical with the question whether Cicero is schmidentical with Cicero (if questions are objects). Does this question arise? Certainly few people are likely to ask it, and fewer still to be in doubt about the answer. If the question 'Is Cicero schmidentical with Cicero?' is not going to trouble them, neither is the question 'Is Cicero schmidentical with Tully?', because it is the same question. (Williams 1989, p. 81)

In this passage, Williams obviously wishes to distinguish an interrogative sentence from its content, and the latter (not the former) would be the question in this picture. This seems to be a fair move, since the sentences "Cicero is schmidentical with Cicero" and "Cicero is schmidentical with Tully" express, according to the objectual account, the same (Russellian) singular proposition, which is likely to also make up the propositional content of the corresponding interrogative sentences. But while Williams' maneuver to identify the questions (as contents) expressed by the respective interrogative sentences seems to be, prima facie, fatal to Kripke's original formulation of the schmidentity argument (see Sect. 1), it is of no use against Ramachandran's reconstruction, since questions (in Williams' sense, i.e. an interrogative sentence's content) are not even addressed in his crucial premise (D3). What figures in premise (D3) (and the corresponding premises (A2) and (A2')) are sentences, not propositions expressed by them (i.e. their contents). Consequently, Williams' argument, in order to be successful, would also have to concern interrogative sentences, instead of their contents.

This means that Williams' argument can simply be answered by providing the proper reconstruction (and reformulation) of Kripke's schmidentity argument, which is in this form immune to Williams' critique. At least if it is, as I would hold, completely implausible to also identify the respective interrogative sentences. This should become even more evident when Williams goes on to say that what may well be a troubling question 'is whether the words 'Is Cicero schmidentical with Tully?' express the same question as the words 'Is Cicero schmidentical with Cicero?'” (Williams 1989, pp. $81 \mathrm{f}$ ) Although I agree with Williams that this is not a question of schmidentity, it still testifies to the fact that the interrogative sentence "Is Cicero schmidentical with Tully?" might very well arise and trouble a speaker of Schmenglish, although "Is Cicero schmidentical with Cicero?" does not. ${ }^{19}$ Nothing more is needed, in the end, to vindicate (D3).

This concludes my defense of the schmidentity argument against criticisms which were brought up in the literature. The presentation of the schmidentity argument,

19 But see the discussion of Paderewski cases in Sect. 5. 
however, is not finished yet because we only discussed the first of two thrusts, identified by Ramachandran. The Schmidentity Defense, governed by the Counterexample Principle, proves that informative identity sentences pose no problem for the objectual account; and by the same token no problem for Millianism. To put the same point differently: Frege's Puzzle, contrary to the conceived view, cannot discredit Millian semantics because Millianism is perfectly compatible with the occurrence of informative identity sentences.

\section{Reconstruction (Part II)}

Although the alleged refutation of purely referential semantics due to Frege's Puzzle is an illusion, it is not entirely unfounded. Frege's Puzzle clearly shows that Millianism, although compatible with informative identity sentences, ${ }^{20}$ does not provide any explanation of this phenomenon. The metalinguistic theory attempts to explain the informativeness of identity sentences, while the objectual account does not have anything to offer in this respect. So, at first glance, the metalinguistic account still seems to be ahead. However, on closer inspection, it is exactly this fact that renders the metalinguistic view contestable by the second thrust of Kripke's argument: the so-called Schmidentity Attack. This line of reasoning follows what Ramachandran calls the Explanatory Principle, which roughly says "that like linguistic phenomena must have like explanations." (Ramachandran 1995, p. 76)

Section 2 dealt with and provided a reconstruction of the Schmidentity Defense which turns on the Counterexample Principle. As the name "Schmidentity Defense" correctly suggests, it defends the objectual account against alleged refutation from the informativity of identity sentences. This and the subsequent section are dedicated to the second step in the schmidentity argument, the so-called Schmidentity Attack, which discredits certain rival accounts on the basis of its basic rationale, the Explanatory Principle. Kripke does not state this principle as explicitly as the Counterexample Principle, but Kripke (2011d, pp. 119f) arguably represents an application of just this principle. It should be kept in mind that the Explanatory Principle merely represents a methodological principle, opting for a unified (linguistic) theory. The Counterexample Principle, in contrast, is a solid linguistic test to check whether an attempted refutation of a semantic theory is viable. Consequentially, the Explanatory Principle might be overruled by other considerations, while the Counterexample Principle does not permit any exceptions.

Thus equipped, the schmidentity argument no longer only strives to defend the objectual account (Schmidentity Defense), but aims to refute the rival view (Schmidentity Attack): Although the metalinguistic theory provides an explanation of the informativeness of identity sentences, schmidentity sentences would also be informative. But because the metalinguistic explanation, by stipulation, cannot be correct for the informativity of schmidentity sentences, the metalinguistic theory cannot really

\footnotetext{
20 The compatibility of Millianism (aka the objectual account) with informative identity sentences is demonstrated by the Schmidentity Defense.
} 
explain the phenomenon. A successful explanation, according to the Explanatory Principle, must also apply to Schmenglish identity sentences. The metalinguistic theory should therefore be rejected. Ramachandran reconstructs the corresponding reasoning as follows:

-Schmidentity Attack-

(A1) The metalinguistic account of identity sentences provides an explanation of the informativeness of English identity sentences.

(A2) Schmenglish identity sentences would also be informative.

(A3) But the metalinguistic explanation, by stipulation, cannot be correct for the informativeness of Schmenglish identity sentences.

(A4) So [-given the Explanatory Principle-] the metalinguistic explanation does not really get to the heart of the informativeness problem.

(A5) Hence, [by the Explanatory Principle again,] the metalinguistic explanation is probably not the correct explanation of the informativeness of English identity sentences.

(Ramachandran 1995, p. 75)

Explanatory Principle Like linguistic phenomena must have like explanations.

The Explanatory Principle applies only if the linguistic phenomena under consideration are indeed alike. The respect in which identity sentences (in English) and schmidentity sentences (in Schmenglish) need to be alike is their informativeness. One might think that the informativeness of schmidentity sentences is not (sufficiently) similar to the informativeness exhibited by identity sentences. Maybe the linguistic phenomena observed in English and Schmenglish when identity sentences are uttered in the respective languages are not alike after all. Or we may at least need to specify how similar the linguistic phenomena need to be, in order to demand for a common (or at least similar) explanation. ${ }^{21}$

Fortunately, this additional argumentative effort is superfluous. Everyone who accepts the Schmidentity Defense must also accept that the linguistic phenomena under consideration (the informativity of identity and of schmidentity sentences) are sufficiently alike. Actually, the Counterexample Principle even demands that it is the very same linguistic phenomenon which is to be looked for in the hypothetical, stipulated language Schmenglish. So, if the informativeness of English and Schmenglish identity sentences is the linguistic phenomenon which figures in the Counterexample Principle, as applied in the Schmidentity Defense, then it is impossible that the Explanatory Principle does not apply for insufficient similarity of the linguistic phenomena in question. If, however, someone is not willing to accept the Schmidentity Defense, then probably no argument I could possibly make at this point would convince this person that the Schmidentity Attack is conclusive.

As it was noted before, the objectual account does not provide any explanation for the informativeness of identity sentences. This is also why the schmidentity

\footnotetext{
21 Thanks to an anonymous reviewer, who pointed out this possibility of criticizing the Schmidentity Attack.
} 
argument — and the Schmidentity Attack in particular — cannot be applied against the objectual account. So, there is no problem of self-application regarding the schmidentity argument. ${ }^{22}$

\section{Consequences}

As Ramachandran correctly observes, the Schmidentity Attack can be set up against every theory which is put forward to explain the informativeness of identity sentences on a semantic level (cf. Ramachandran 1995, p. 77). He provides a Schmidentity Attack against a Fregean theory (distinguishing between sense and reference of an expression; cf. Ramachandran 1995, pp. 77 f), but I prefer to present a version which is set up against Kent Bach's Nominal Description Theory (NDT), ${ }^{23}$ which is more closely related to a Russellian than to a Fregean treatment of expressions. The core idea of NDT is that every name or referring expression " $\mathrm{N}$ " is connected to a description of the form "the bearer of "N'", so that e.g. "Aristotle" has to be analyzed as "the bearer of (the name) 'Aristotle"'. To set out the Schmidentity Attack against NDT seems convenient because NDT represents a kind of minimal descriptivist theory by connecting a name with a description which arguably every speaker has at her disposal. Although Kripke provided strong arguments against descriptivist theories in Naming and Necessity, it is not entirely clear whether his arguments are also applicable against NDT.

Especially Kripke's epistemic argument can be easily answered by a proponent of NDT since a speaker would, according to NDT, only know a very moderate truth about an individual by learning the name of it. A speaker would e.g. know a priori that Aristotle is called "Aristotle," but the speaker would not know a potentially surprising fact such as e.g. that Aristotle taught Alexander the Great. Whether Kripke's semantic argument is viable against NDT heavily depends on the question how exactly a relation like "...is called..." or "... is the bearer of..." has to be understood and therefore demands further discussion. (Cf. Fraissler 2014, pp. 106f n.) Since Bach explicitly states that "NDT is a theory of the meaning of names" (Bach 1987, p. 160), but not a theory about reference fixing, Kripke's non-circularity condition (cf. Kripke 1980, p. 68) is no threat for NDT. But NDT has to be vindicated against Kripke's famous modal argument. This could be done quite easily by changing the description associated with a name slightly to a rigidified description like "the actual bearer of ' $\mathrm{N}$ ", which shares the relevant aspects of its modal profile with the corresponding name "N". This might have negative repercussions for countering the epistemic argument, but Bach prefers a different defense against the modal argument anyway (cf. Bach 2002, pp. $84 \mathrm{f}$ and esp. n. 29 on p. 98). But even if NDT can withstand Kripke's arguments against descriptivist theories, it is still exposed to the schmidentity argument;

\footnotetext{
22 I want to thank Christian Nimtz for quite emphatically pointing out this possible misconception to me during the Q \& A session after the talk in Osnabrück.

23 Ramachandran also considered NDT in his paper from 1989, but he did not discuss this theory in connection with his elaborate distinction between Schmidentity Defense and Schmidentity Attack, which only appears in his 1995 paper.
} 
which of course cannot refute NDT altogether, but can at least deprive it of some of its alleged benefits.

— Extended Schmidentity Attack —

$\left(\mathrm{Al}^{\prime}\right)$ NDT provides an explanation of the informativeness of English identity sentences.

(A2') Schmenglish identity sentences would also be informative.

(A3') But NDT's explanation, by stipulation, cannot be correct for the informativeness of Schmenglish identity sentences.

(A4') So-given the Explanatory Principle-the NDT explanation does not really get to the heart of the informativeness problem.

(A5') Hence, also by the Explanatory Principle, NDT does probably not provide the correct explanation of the informativeness of English identity sentences.

At this point, one characterization of Schmenglish needs to be made explicit: Schmenglish is conceived of as being in agreement with Millian semantics. Proper names in Schmenglish are therefore mere tags which pick out their referent, but do not have any semantic content beyond their referring function. ${ }^{24}$ Since NDT is explicitly stated as a theory of meaning (cf. Bach 1987, p. 160), it is excluded as a correct description of the semantics of Schmenglish from the outset.

To prevent an occasional misconception, I would like to add that by this definition informativity is of course not stipulated away. If what I have to say about informativity on the following pages is true, informativeness could not even possibly be eliminated by any semantical fixations. Schmenglish is just so constructed to make it obvious that informativity cannot be a semantic feature of this language - and consequently, this probably holds true for every other possible language as well.

As a related but different objection, someone might be tempted to think that Schmenglish is not even a possible language, since schmidentity sentences would be stripped of their (potential for) cognitive significance and informativity, which makes the characterization of Schmenglish incoherent. As a reply to this kind of reasoning we must note that Schmenglish and schmidentity sentences are by no means defined as being cognitively insignificant. Schmenglish is merely defined as a language whose cognitive significance is not due to its semantics. Arguing that Schmenglish is incoherent or impossible because it lacks cognitive significance (or Fregean senses) would presuppose that cognitive significance or informativity must be a matter of semantics, and therefore beg the question against the position that informativity is due to the pragmatics of a language-which is the position defended in this paper (see below). In other words, the identification between sense and cognitive significance usually made by Fregeans is questioned, since Schmenglish names do not have senses (or other kinds of descriptive content), but schmidentity sentences containing proper names can still be cognitively significant (i.e. informative).

\footnotetext{
24 This stipulation regarding the semantics of proper names in Schmenglish is analogous to the stipulation of definite descriptions in Russell English presented in Sect. 2.
} 
Up to this point, I absolutely agree with Ramachandran and take his reconstruction of the schmidentity argument to be entirely adequate. ${ }^{25}$ But I am rather skeptical about his evaluation because Ramachandran takes the fact that the schmidentity argument is effective against every competing semantic theory "pretty much [as] a reductio of the [Schmidentity Attack]." (Ramachandran 1995, p. 78) He seems, however, to come up with this conclusion only because he takes it for granted that informativity has to be accounted for (at least partially) in terms of semantics.

I think, pace Ramachandran, that the schmidentity argument's effectiveness against every semantic explanation of the informativity phenomenon by no means tells against that argument. I am therefore willing to draw a very different conclusion from

\begin{abstract}
25 One worry that might be put forward against Ramachandran's reconstruction of the schmidentity argument—namely against his distinction between Schmidentity Defense and Schmidentity Attack-is that there seems to be no trace of the so-called Schmidentity Attack in Kripke's most elaborate application of a schmidentity-like argument, i.e. in his argument concerning Donnellan's distinction between attributive and referential uses of definite descriptions. This holds true for Kripke (2011d) as well as for Kripke (2013, pp. 115-123). Of course, this merely concerns an exegetical question, but still, one might wonder: Why did Kripke not additionally strengthen his defense of Russell's analysis by a charge against Donnellan's account by extending his argument with an adequately adapted version of the Schmidentity Attack? I tend to agree with Ramachandran that "one could—at no extra cost—discredit the ambiguity thesis itself by means of an argument mirroring the Schmidentity Attack." (Ramachandran 1995, p. 76) It is not trivial to decide whether Donnellan is best to be interpreted as claiming a semantic ambiguity in definite descriptions. On the one hand, a great deal of his discussion in 'Reference and Definite Descriptions' strongly suggests that his distinction is a semantic issue, but on the other hand, he stays explicitly reluctant to talk about a semantic ambiguity there. If we follow Donnellan's assessment of attributive and referential uses of definite descriptions as pragmatically ambiguous, a Schmidentity Attack-like argument cannot even be applied against Donnellan, since there might not even be a real disagreement between Russell's analysis and Donnellan's findings (at least not on the semantic level). But if we take a semantic ambiguity to be in question here, then it appears to be puzzling why Kripke did not use the whole force of his own argument in this case. Could Kripke's strange lack of application of a Schmidentity Attack-like twist at this point maybe cast doubt on whether Ramachandran's reconstruction of the schmidentity argument is really accurate? I do not think that this is the case, because Kripke in fact does use the Explanatory Principle also in his paper about 'Speaker's Reference and Semantic Reference' to discredit any alleged semantic ambiguity in definite descriptions. Since the Explanatory Principle lies at the heart of the Schmidentity Attack, Kripke in fact kind of endorsed this argumentative strategy also in this case. What is missing there for a full blown reapplication of a Schmidentity Attack is that Kripke does not appeal to linguistic intuitions turning on a thought experiment in regard to a speaker community of a stipulatively introduced language (such as Russell English or Schmenglish). Kripke argues that his own distinction between speaker's reference and semantic reference is able to account not only for Donnellan's cases but also for sufficiently similar phenomena which appear in examples involving proper names instead of definite descriptions. Since the respective phenomena in connection with proper names on the one hand and definite descriptions on the other are supposed to be alike, they should — according to the Explanatory Principle—have the same explanation. So, if one is not willing to invoke a semantic ambiguity for proper names then one also should not posit a semantic ambiguity in the case of definite descriptions. This line of reasoning still seems to be quite similar to the Schmidentity Attack, but Kripke simply does not have to make recourse to a stipulatively introduced, hypothetical language because he brings a new element (proper names) into the discussion here. Without this resource, he could still have applied a Schmidentity Attack against the semantic ambiguity thesis. But this would merely have discredited Donnellan's theory without the advantage of strengthening Kripke's own account. I guess that this sufficiently explains why the missing Schmidentity Attack does not tell against the accuracy of Ramachandran's reconstruction-at least as far as exegetical matters are concerned.

Further worries might emerge from the fact that an explicit restatement of the schmidentity argument is to be found also in Kripke (2013, pp. 114f), where no hint of the Schmidentity Attack can be detected whatsoever. But it is certainly of interest here that Saul Kripke himself expressed his sympathy towards Ramachandran's reconstruction (as I explained it) during a short personal conversation in the summer of 2015 in Vienna.
\end{abstract}


Ramachandran's, namely that the schmidentity argument teaches us that informativity cannot be explained by a purely semantic theory at all. Thus, informativity in regard to identity sentences cannot be a semantic issue. Hence, by ruling out every semantic account of informativeness, the schmidentity argument outlines what kind of phenomenon informativity really is - or rather, which kind of phenomenon it is notby indicating where the phenomenon itself, as well as any successful explanation, cannot be located: namely on the level of semantics.

Of course there also exists a useful semantic notion of informativity. That the sentence "Today is Monday and it is raining" is more informative than the sentence "Today is Monday or it is raining"-more generally: that $\ulcorner P \wedge Q\urcorner$ is more informative than $\ulcorner P \vee Q\urcorner$ —is clearly due to semantics. But this semantic notion of informativity is of no help when it comes to identity sentences. In what follows, everything I say about informativity (i.e. informativeness, see n. 4 in Sect. 1) should be understood as relating to the phenomenon in question as it occurs in connection with identity sentences and their respective statements/utterances. ${ }^{26}$

The schmidentity argument provides, strictly speaking, only a negative outcome to the effect that Frege's Puzzle and the phenomenon of informativity in identity sentences cannot be explained semantically, leaving open the possibility that a syntactic treatment might be the right option. David Kaplan prompts this possibility when he asks the question: "Could it be that the elusive cognitive difference between believing that Hesperus is Hesperus and believing that Hesperus is Phosperus [sic!] rests on nothing more than syntax?" (Kaplan 1990, p. 93) Although Kaplan phrased his question in terms of belief (which ostensibly clashes with the announced focus of this paper-see $n$. ii of the abstract), it can easily be reformulated as a question about the difference in informativeness of sentences without any substantial loss. Nathan Salmon would strictly oppose this option when he talks about "the wrongheaded temptation to identify the information value of a name with the name itself" (Salmon 1986, p. 170, n. 1). ${ }^{27}$ If Salmon's assessment is correct—and I think it is—, we should conclude that pragmatics is the right place for informativity.

One way to rule out syntactic theories of informativity is to consider so-called Paderewski cases (cf. Kripke 2011c, p. 154). Peter, in Kripke's example, might clearly wonder at some point whether Paderewski is Paderewski; or put differently, whether "Paderewski = Paderewski" is true. Instead of reiterating Kripke's Paderewski example, I prefer to quote a convenient analogous case from Freitag (2009, p. 134):

A Philosophy student [let's call him "Peter"] hears about Saul Kripke twice a week, once in his seminar on modal logic and once in his class on Wittgenstein's Philosophical Investigations. He rightly wonders whether it is one and the same person having such extraordinary thoughts. Upon looking in the Web, he finds out that this is indeed the case. 'Kripke $=$ Kripke' has been found out aposteriori. ${ }^{28}$

\footnotetext{
26 I want to thank Christian Piller for pointing this out and forcing me to be clearer in this regard.

27 For another syntactic account to solve Frege's Puzzle, see Fodor (2008, pp. 60 f).

28 A properly adapted version of John Perry's (2015, pp. $196 \mathrm{ff}$ ) example about John Etchemendy, as well as countless other variations of Paderewski cases, could of course be used to make just the same point.
} 
It would clearly be a mistake, I think, to analyze this sentence as having the syntactic structure $\ulcorner a=b\urcorner^{29}$ rather than $\ulcorner a=a\urcorner$. We should resist any possible temptation to relativize "Kripke $=$ Kripke" to Peter's or anyone else's idiolect to say that the first occurrence of "Kripke" might represent a different name from the second occurrence. Peter, when considering whether "Kripke = Kripke" is true, in fact wonders about the truth of a sentence of the form $\ulcorner a=a\urcorner$, although Peter is of course ignorant of the real syntactic form. That the question arises for Peter is, as mentioned towards the end of Sect. 3, sufficient for the sentence to be informative. I take David Kaplan's (1990) common currency conception of words to be generally on the right track regarding the question how names should be individuated. Although his theory allows for distinct words with identical pronunciation, spelling, and semantic value, I entirely agree with Kaplan that in this scenario (and other Paderewski cases) there is only one name involved (cf. Kaplan 1990, p. 108). So, even sentences of the syntactic form $\ulcorner a=a\urcorner$ can be informative. ${ }^{30}$ Since there does not seem to be a steady connection between syntactic form and informativity, we are left with very dim prospects for any purely syntactic theory of informativeness. Even Kaplan's own treatment of Paderewski cases explains the situation, correctly I think, with recourse to what a speaker like Peter (mistakenly) thinks (cf. Kaplan 1990, p. 110), which shifts the whole discussion towards pragmatics.

The general guiding idea for a pragmatic account of informativity might be as simple as this: Just as I can communicate my demand to close the window or to turn up the heater by uttering the sentence "It's cold in here," without this demand being the semantic meaning of the sentence, I can communicate the information that "Hesperus" and "Phosphorus" name the same thing by uttering the sentence "Hesperus is Phosphorus," without this information being contained in the meaning of the sentence. All this follows the Gricean insight that by uttering a sentence, we can convey information which does not belong to the semantic content of the sentence uttered. ${ }^{31}$ To put the relevant distinction in Nathan Salmon's words:

It is extremely important in dealing with Frege's Puzzle and related philosophical problems to distinguish the notion of the information content [or semantically encoded information] of a sentence on a particular occasion of its use from the notion of the information imparted [or pragmatically conveyed information] by the particular utterance of the sentence. The first is a semantic notion, the second a pragmatic notion. (Salmon 1986, p. 58)

The conclusion that informativity is a pragmatic issue can be strengthened by independent arguments for the fact that informativeness is an epistemic and person-relative feature. ${ }^{32}$ Consider e.g. the sentence "Superman can fly" which Lois Lane would not find very informative, although it surely would be interesting to somebody who had never heard of Superman. This is simply because "[h]ow informative we find a sentence

\footnotetext{
29 Or "Paderewski ${ }_{I}=$ Paderewski $_{I I}$ ", as suggested for example in Larson and Ludlow (1993, pp. 318f).

30 The same claim is also made in Wettstein (1989, p. 333).

31 Thanks to Tristan Haze who made me be more explicit in this regard.

32 Cf. Almog (2005, pp. 512 ff), where this point is also emphasized. For a strictly opposing view, cf. Yagisawa (1993).
} 
depends, unsurprisingly, on what we already know" (Ramachandran 1989, p. 469), which by itself inclines me to deem informativeness a pragmatic notion. So anyone who wants to develop a (purely) semantic theory should not bother with accounting for informativity, which is, just as the corresponding worries in regard to Frege's Puzzle, relevant only on a pragmatic level; and consequently needs to be treated exclusively by a pragmatic account, which is needed anyway to support and complement a purely semantic theory like the objectual account-or in other words: referentialism. I take this result to be a fundamental methodological restriction not only for semantical theorizing, but also for every attempted explanation of the informativity phenomenon and/or solution of Frege's Puzzle.

We saw that the schmidentity argument is a very powerful tool because a Schmidentity Attack can be set up against every semantic explanation of informativeness in identity sentences. But, one might wonder, could the same strategy not also be applied against pragmatic theories of informativity $?^{33}$ The answer to this question is clearly negative, because the pragmatics of a language cannot simply be stipulated as a language's semantics can. The pragmatic aspects of a language are not arbitrary as a language's semantic aspects are. This is the reason why informativeness cannot simply be stipulated away, and why pragmatic explanations of informativity are not suceptible to the Schmidentity Attack (see also n. 25 above). ${ }^{34}$

I do not wish to commit myself to any particular pragmatic theory which could fulfill this role. But still, in order to indicate some possibilities I have in mind, I would suggest an account along the lines of pragmatic presupposition, presented by Robert Stalnaker (e.g. in Stalnaker 1999b; Stalnaker 1975; and Stalnaker 1999a); or an attempt to apply the Gricean concept of implicature to this issue. Informativeness, if treated as Gricean implicature, should probably be categorized, pace Bach (1999), as conventional implicature. If we suppose that the implicated information is a metalinguistic proposition, then informativity appears to be non-cancelable (since you cannot say "Hesperus is Phosphorus, but the names 'Hesperus' and 'Phosphorus' do not co-refer" without contradicting yourself) and detachable (from the Millianist standpoint "Hesperus is Phosphorus" and "Hesperus is Hesperus" are semantically/truth-conditionally equivalent, but while an utterance of the former sentence gives rise to an informative implicature, this is not the case with the latter; viz. you can say the same thing without any implicature of informativeness - the implicature can be detached). Detachability and non-cancelability sum up to the characterization of conventional implicature. An apparent problem of this categorization of informativity as conventional implicature in the context of this paper is that conventional implicature (in contrast to other kinds of implicature, most prominently conversational implicature) is usually considered as a part of an expression's literal meaning, which should consequentially make it a part of semantics. Nonetheless, the contribution to meaning made by conventional implicature is truth-conditionally irrelevant. So, if we wish to stick with truth-conditional semantics, we might very well acknowledge this non-truth-conditional contribution to meaning, but we should not qualify it as semantic. (For an elaborate account of how to

\footnotetext{
33 I wish to thank an anonymous referee for bringing up this question.

34 Whether the syntax of a language can be stipulated as its semantics, can remain an open question. Syntactic accounts of informativity were ruled out on independent grounds in this paper anyway.
} 
apply Gricean implicature and Wilson \& Sperber's relevance theory in order to defend Millianism, see Båve 2008). But at least two considerations indicate that conventional implicature does not perfectly fit as a theoretical tool to analyze informativeness. The first problem is that it should be possible for the uttered sentence/proposition to be true, although what was implicated is false. Due to the different modal profiles of what is said (that Hesperus is Phosphorus) and what is implicated (that "Hesperus" and "Phosphorus" co-refer) this holds true in a certain way; but not in the right way, since "Hesperus is Phosphorus" cannot be true if "Hesperus" and "Phosphorus" do not co-refer. Secondly, because conventional implicature depends on the conventional meaning of certain terms and not on the context of an utterance, this kind of implicature is in-calculable, viz. it is not derivable from contextual features. This makes conventional implicature unfit to cover the wide variability of possible pieces of information which can be conveyed by an utterance of "Hesperus is Phosphorus," depending on the conversational context-from the highly context dependent that the planet we talked about yesterday is the last visible celestial body in the morning sky to the virtually context invariable "Hesperus" and "Phosphorus" refer to the same thing. Maybe these deficiencies can be remedied, but in the light of these considerations pragmatic presupposition is probably preferable to account for informativeness. Either the metalinguistic piece of information that "Hesperus" and "Phosphorus" co-refer can be presupposed directly, or a more general linguistic principle which guarantees that "Hesperus is Phosphorus" is true iff "Hesperus" and "Phosphorus" co-refer might be pragmatically presupposed. The latter is more easily accommodated in the common ground (cf. Stalnaker 2002) or transferred to the salient or active context (cf. Kripke 2011b) and makes the metalinguistic piece of information easily derivable for any participant in the conversation. Also, pragmatic presupposition is more flexible than conventional implicature, so that all kinds of contextually dependent and perhaps idiosyncratic pieces of information possibly conveyed by an utterance of "Hesperus is Phosphorus" can easily be accounted for.

That informativity is not a semantic topic and consequently is not to be treated by semantics has been, I think, additionally obscured by a terminological issue-besides a tacit but persistent presupposition in favor of the opposite view, coming from the Fregean tradition. In the discussion of informativity and cognitive significance, especially in connection with Frege's Puzzle, informativeness is usually contrasted with triviality. In accordance with this paper's outcome, I think that triviality is not the opposite of informativity and therefore propose to differentiate two separate distinctions: On the one hand "trivial" should be opposed to "non-trivial," and separate from this dichotomy "informative"/“uninformative" is an independent contrast. The core of the distinction between trivial/non-trivial and informative/uninformative is where these distinctions belong: (non-)triviality is meant to be a purely syntactic property while (un-)informativeness shall be a pragmatic feature.

In discussing Frege's Puzzle, the difference between informative and trivial sentences was traditionally depicted by juxtaposing the sentence schemas $\ulcorner a=a\urcorner$ and $\ulcorner a=b\urcorner$. Respecting the distinction mentioned in the previous paragraph $\ulcorner a=a\urcorner /\ulcorner a=b\urcorner$ is a representation of the trivial/non-trivial-distinction, but has nothing to do with informativity. Sentences of either syntactic form have the potential 
to be informative; ${ }^{35}$ but whether a sentence or statement will in fact be informative for anyone or not depends on this person's epistemic status. If I find e.g. "Hesperus is Phosphorus" or "Cicero is Tully" informative or not, depends upon whether I know the relevant facts about the planet Venus and Marcus Tullius Cicero. Either way, these sentences are, according to the proposed usage of the term, of course not trivial. But whether or not they are also informative cannot be determined by their logical or syntactic form alone, nor with the additional knowledge of the relevant semantic facts. This is because informativity, in contrast to triviality, cannot be determined for sentences or even utterances of sentences tout court. Informativity can only be ascertained of a statement in regard to a specific context and a specific person.

This attempt to distinguish informativity and triviality can be seen as a loosely applied form of Schmanalysis, as it is discussed in Petersen (2008). Since I agree with Ramachandran's interpretation (though not to his evaluation) of the schmidentity argument, I take Petersen's reconstruction to be a severe misunderstanding of Kripke's argumentative strategy. But it was at least a quite fruitful misunderstanding, I guess; and Petersen is probably not troubled too much by the accusation of not having represented Kripke's intentions accurately, since he explicitly states that the argumentation he wants to defend comes in "a more general formulation than Kripke intended." (Petersen 2008, p. 291)

Correspondingly, what I propose is a clarification (or even surmounting, if you wish) of the traditional notion of informativity by clearly distinguishing triviality as a purely syntactic matter from informativity proper, we may call it, which is a strictly pragmatic issue. The traditional concept of informativeness intermingled the syntactic and the pragmatic level by not keeping triviality and informativity proper apart, and so blurred the whole topic. But if we are interested in informativity, we should focus on pragmatics and leave considerations concerning syntactic and especially semantic topics aside, since they are quite remote from questions of informativity proper.

In summary, I have argued that the schmidentity argument's true value consists in its potential to demonstrate the inadequateness of attempts to account for Frege's Puzzlei.e. for informative identity sentences - in terms of semantics. Thus, the schmidentity argument provides justification for the common Millianist's turn to pragmatics ${ }^{36}$ when confronted with cases of informative identity sentences and other cases related to cognitive significance. The genuinely new insight in this respect is that this "pragmatic move" is shown to be not only one possible solution for Frege's Puzzle, but it is in fact the only possible route to take. In the light of the foregoing discussion this seems to be an inevitable conclusion to draw, since every semantic attempt will be disqualified by the schmidentity argument (and since it seems reasonable on independent grounds

\footnotetext{
35 Since, as discussed above in connection with Paderewski cases, even sentences of the form $\ulcorner a=a\urcorner$ can be informative, the label "trivial" might be misleading if it suggests that a trivial sentence cannot be informative. I will nonetheless stick to the traditional diction here, which will not do any harm as long as it is remembered that syntactic form alone does not allow any inference about informativeness.

I wish to thank an anonymous referee from Synthese for pointing out that Paderewski cases might be relevant at this point. This motivated the aforementioned discussion and prevented me from mistakenly claiming that only non-trivial sentences can be informative. The referee in question is of course not responsible for the conclusions I draw from Paderewski examples.

36 For arguments against non-pragmatic versions of Millianism, see Onofri (2013).
} 
to locate informativity in the domain of pragmatics, instead of considering it a part of syntax). In contrast to this, which I take to be a resolute outcome, the previous suggestion to use "informativity" and "triviality" in the manner described above in order to overcome the traditional dichotomy between informativity (improper) and triviality in its allegedly semantic sense, really is just that: a suggestion; which I hope can help to clear up the discussion a little bit. But if this proposal is rejected, it won't matter for this paper's central claim.

\section{Excursion: semantic relationism}

I would like to rest my case at this point, but precisely this central claim-that informativity cannot be accounted for in terms of semantics-stands in stark contrast to a theory which has gained growing attention during the last few years. Therefore, I feel urged to say at least some words about Kit Fine's theory of semantic relationism, since Fine emphatically claims to have provided a semantic solution exactly to Frege's and to related philosophical puzzles with his account. ${ }^{37}$ But even if semantic relationism might well be a semantic theory overall, the puzzles it was proposed to solve are not even settled on the semantic level within this theory. This is because Fine's central notion of coordination, which in general does all the work of handling the troubles related to informativity, is not a semantic notion. In fact, Fine's use of "coordination" seems to vacillate between syntax and pragmatics, and so it suffers from the same deficiency, already diagnosed in regard to the traditional concept of informativity (improper).

Although Fine introduces coordination as "the very strongest relation of synonymy or being semantically the same" (Fine 2007, p. 5), his application of this notion tells a very different story. For example, according to his account "the syntactic object of evaluation will no longer be a sequence of expressions but a coordinated sequence of expressions" (Fine 2007, p. 30; emphasis added) and "the syntax itself becomes relational and coordination at the semantic level should be seen to reflect an underlying coordination at the level of the syntax." (Fine 2007, p. 31; emphasis added) This sounds, at least to my ears, much as if coordination was in fact a genuinely syntactic issue. In an earlier text, Fine also says that "patterns [of coordination] must be explicitly used as syntactic inputs to the semantic method of evaluation." (Fine 2003, p. 629; emphasis added) Now I wonder how something could possibly be used as syntactic input if it belongs to semantics. Fine also claims that one can make "use of coordination at the level both of syntax and of semantics" (Fine 2007, p. 31), but it seems that only signs and never meanings (i.e. referents, since Fine claims to advocate a referentialist position which includes a good deal of Millianism; cf. Fine 2007, p. 5 and p. 53) can be coordinated. This is because it is of no use (and probably also makes no sense) to say that Cicero is coordinated with himself when we refer to him by means of a coordinated pair of names (e.g. "Cicero" and "Cicero"), but Cicero is not coordinated

\footnotetext{
37 Readers who are not drawn towards Kit Fine's theory anyway can skip this section without great loss for the overall argument, as already indicated in $\mathrm{n}$. iii in the abstract.
} 
with himself, if we use uncoordinated names of him (e.g. "Cicero" and "Tully"). ${ }^{38} \mathrm{~A}$ proposal along these lines of coordinating a thing with itself cannot be what Fine had in mind, and since it should suffice to coordinate signs on the level of syntax to guarantee sameness of reference or-according to Fine's own declaration-synonymy, which seems to be the main purpose of coordination, I cannot see what a differentiation between syntactic and semantic coordination is supposed to amount to. ${ }^{39}$

I am also not convinced by Fine's attempts to show that the analogous phenomenon of two names representing their referent as the same-which he prefers to discuss in the context of Frege's Puzzle instead of coordination-cannot be syntactic. (Cf. Fine 2007, p. 41.) Fine mentions Kaplan (1990) at the outset of his discussion as a champion of the position that the phenomenon in question is pre-semantic, i.e. syntactic. But in the course of his very quick denial of this position, he completely ignores the outcome of Kaplan's paper, which offers a framework to individuate (common currency) names independently of their typographic identity and of co-reference. ${ }^{40}$ With this result in hand, Fine's demur that coordination in these cases consists simply in the identity of names becomes obsolete. This of course does not hold for the case of anaphora, which is also mentioned in the same passage. But the example Fine uses there is

38 This claim evidently needs to be qualified if we take into account Fine's "ontology of occurrences" (Fine
1989, p. 236), which he utilizes in his theory of semantic relationism. If we suppose not that the referents
are coordinated with themselves, but that their occurrences are coordinated with each other, we get at least
a comprehensible account. Still, this solution comes with a big drawback, since it would force us to claim
that names do not refer to the objects they are meant to refer to, but to occurrences of these objects instead.
(Cf. Wezenberg 2015, p. 111.) I guess that semantic revisionism of this kind might be too high a price to
pay, since it amounts to saying that different occurrences of a name do not refer to the same thing, but to
the respective different occurrences of a thing (in a proposition, for example). A proposal along these lines
jeopardizes our ability to repeatedly refer to one and the same thing in discourse, since a name's meaning
must change with every new occurrence.

39 Worries of a different kind about coordination on the level of semantics are fostered by Scott Soames who raises a battery of problems against Fine's semantic relationism, meant to cast doubt on the existence of coordinated propositions in Fine's sense. (Cf. Soames 2012; and Soames 2014, p. 118.) I do not wish to take a stance on the question whether Soames convincingly demonstrates that Finean coordinated propositions do not exist, since I take this matter to be of minor importance as far as our discussion is concerned. The schmidentity argument can and should (see the discussion of Williams' objection in Sect. 3) be stated without any recourse to propositions, i.e. semantic contents of sentences. (This way of reconstructing the argument is in good agreement with Kripke's general reservations against talking about propositions in domains of relevance for our investigation; cf. Kripke 1980, pp. 20f.) This means that the schmidentity argument is independent of any commitment regarding propositions. Therefore, it should be possible to formulate a Schmidentity Attack turning on a version of Schmenglish which does not incorporate coordination schemas; since if coordination/representing-as-the-same were a basic or primitive semantic feature (which seems to be something Fine is committed to, cf. Soames 2014, p. 117-although Soames treats representing-as-thesame as an attitude, which already suggests that we might not be dealing with semantics here), this could be unproblematically stipulated. As long as it cannot be shown that coordinated propositions are a necessary ingredient of every possible language which is rich enough to include informative identity sentences, this would show that coordination/representing-as-the-same does not get to the heart of the problem and is therefore probably not the correct explanation of informative identity sentences.

40 Textor (2007) elaborates on Kaplan's results and provides an account of syntactically simple names which are individuated by their genesis. Also, speakers' intentions do not play any role in Textor (2007), while they still often appear in Kaplan (1990). For a critical evaluation of Kaplan's common currency conception of words, including the role of speaker's intentions, see Hawthorne and Lepore (2011) and Kaplan (2011) as a rejoinder to the former. Kaplan (2011, p. 505) also states that "[he] was aiming at a syntactical/lexical version of what Kit Fine has, more recently, called coordination." But mind the short discussion of Paderewski cases in Sect. 5 regarding the prospects for a syntactic account of informativity. 
of no use in establishing his claim that representing-as-the-same cannot be treated in syntactic terms. ${ }^{41}$ Hence, Fine's attempts to argue against the objection that the central theoretic tool of semantic relationism-i.e. coordination or representing-asthe-same-is syntactic or at least constituted by a syntactic feature (cf. Fine 2007, p. 42) are, to say the least, unsatisfactory.

In contrast to all this, I think that Nathan Salmon is quite right to emphasize that coordination (or representing something as the same thing) does always occur with respect to a "cognizer" and is therefore a pragmatic phenomenon (cf. Salmon 2012). ${ }^{42}$ Thus it seems that coordination is just like informativity in its traditional improper sense a blurred notion-oscillating between syntax and pragmatics—which needs further clarification and differentiation if it shall serve theoretical advance. At least, I think that there is no compelling evidence that Fine really proposed a semantic solution to Frege's Puzzle or to questions of cognitive significance; which, as I have tried to show, is not even possible. So, the interpretation of the schmidentity argument, as it is suggested in this paper, can prevail in spite of Fine's proposal.

\section{Bigger picture}

I argued that the schmidentity argument not only rescues the objectual account from being challenged by Frege's Puzzle (Schmidentity Defense), but also discourages semantic accounts of informativity altogether (Schmidentity Attack). Approaches to solve Frege's Puzzle which are not clearly subject to the schmidentity argument can usually be revealed as not being really semantic solutions at all, as shown with Fine's semantic relationism in the previous section. A quick consideration of a less prominent attempt to semantically account for Frege's Puzzle will lead this concluding outlook to its central topic: the proper notion of semantics en gros.

Takashi Yagisawa (1993) emphatically claims that Frege's Puzzle must be treated semantically, because informativeness is a semantic notion. Yagisawa's notion of semantics, however, damagingly conflates semantic with metasemantic ${ }^{43}$ issues. This

\footnotetext{
41 Fine states that "[w]e might also observe that in cases of anaphora (as when I say 'I saw John, he was wearing a bowler hat'), we can have two expressions representing an object as the same without the expressions themselves being the same [...]". (Fine 2007, p. 41) While this is certainly true and Fine makes an interesting as well as relevant observation, his sample sentence is a red herring. It has to be acknowledged that anaphora is a vexed issue and there are several complicated cases of anaphora which are known to pose serious problems for traditional accounts, trying to analyze anaphora in terms of logical form alone. But Fine's example is not one of these problematic cases. His sample represents a pronoun of laziness (cf. Geach 1980, p. 151), which is probably the best understood and least problematic case of pronominal anaphora. Pronouns of laziness can easily be accounted for in purely grammatical terms. So, Fine's case in point cannot help his argument that representing-as-the-same is not constituted by a syntactic feature or relationship, albeit Fine maybe could have made a stronger point by citing a better example. (Note also that I stick to Geach's original definition of the term "pronoun of laziness" from Geach (1980). This is an important caveat, because according to his later, extended use of the term in question—cf. Geach 1964 p. 172-, it also comprises cases which are intuitively not easily treated syntactically.)

42 Also Scott Soames charges Fine (on different grounds from Salmon's) with conflating semantics with pragmatics in his treatment of coordination and representing-as-the-same. (Cf. Soames 2012 p. 115 n. 6.) 43 I basically follow Burgess and Sherman (2014) in their attempt to explicate metasemantics, and distinguish metasemantic from semantic questions.
} 
eventually leads him to build his solution for Frege's Puzzle on a semantic theory which deprives names of any semantic content (cf. Yagisawa 1993, p. 149). "Informativeness" is defined as being not analytic, and a sentence is analytic if its truth value is entailed by semantics alone (cf. Yagisawa 1993, p. 136). Correspondingly, "[...] as a matter of definition, a sentence is informative iff semantics does not entail its truth value." (Yagisawa 1993, p. 138) Since names do not have semantic content according to Yagisawa's semantic theory, semantics will not entail the truth value for any sentence where a name occurs (transparently). Any such sentence is therefore informative, according to this theory. Yagisawa conceives of his semantic theory as being in agreement with Millianism, and he therefore concludes that "Millianism gives a straightforward semantic account for the informativeness pointed out by Frege."44 (Yagisawa 1993, p. 136) To achieve this, Yagisawa expels reference, assignment (of values), and even truth from semantics, if names are involved. This highly revisionist semantic account certainly demands for more justification than a dubious solution for Frege's Puzzle could possibly provide. But be that as it may. This short exposition should make clear that a proper understanding of what is or is not a semantic issue unsurprisingly is of paramount importance when it comes to Frege's Puzzle and informativity.

The whole discussion about schmidentity concerns not only Frege's Puzzle and informativeness, but cuts much deeper. The ultimate ground where this discussion belongs is, in my view, the question of what semantics really is about. Does the semantic enterprise have to account for questions of cognitive significance, as Frege would have it? This would mean that semantics is primarily concerned with the relation between language and our thinking about the world (call this the representational approach). Or should semantics only deal with the relation between language and the world itself (call this the referential or denotational approach), i.e. disregarding how or what we think about the world? I tend to agree with Howard Wettstein that it is this question about how to understand semantics (and not the question whether or not there is something like Fregean sense) which is the real and fundamental point of argument and disagreement between the so-called Neo-Fregeans and proponents of the New Theory of Reference. One could say that it is a criterion of adequacy for Fregean semantics to account especially for questions of informativity and for questions of cognitive value in general. Although it has often been tried to reconcile New Theory of Reference accounts with the Fregean adequacy criterion for semantics by accounting for questions of cognitive significance, I take it (following Wettstein 1986; and Wettstein 2004 esp. chap. 6; cf. also Salmon 1986 p. 66) to be mistaken from the outset to attempt such reconciliation, because the core of the New Theory of Reference seems to be a reconsideration and reinterpretation of the purpose and task of the semantic enterprise as a whole. From the referentialist point of view, this reconsideration must lead to the conclusion that semantics ought to deal with the relation between language and the world, and leave the topic of how language is related to our understanding of the world completely aside. This includes disregarding issues of cognitive value and informativity in the course of the semantic enterprise

\footnotetext{
$\overline{44}$ Emphasis added. As should be clear at this point, I disagree. Millianism (as a semantic theory) is viable exactly because it does not include any account of informativity.
} 
altogether. ${ }^{45}$ Although these topics of course shall not be neglected tout court, they can and should (and, in accordance with this paper's claim, even have to) be omitted as long as we are dealing with semantic questions only. ${ }^{46}$

In conclusion, we can say that as far as the proposed interpretation and reconstruction of the schmidentity argument is correct, these findings bear a considerable impact on the dispute between semantic internalism and externalism-roughly demarcated along the question whether mental content (narrowly construed) is fit to determine reference or extension. Although neither the representational approach to semantics and semantic internalism on the one hand, nor the referential/denotational approach to semantics and semantic externalism on the other hand are identical, they are still closely connected and naturally go together. In fact, the representational approach to semantics often motivates semantic internalism and fosters reservations against externalist semantic theories. The schmidentity argument shows that (and why) the complex of considerations surrounding Frege's Puzzle cannot provide reasons to abandon Millianism or (direct) referentialism. Additionally, the schmidentity argument carries the argumentative burden to show that (and why) descriptivist or, generally speaking, internalist semantics only seemingly solve Frege's Puzzle and related phenomena. And, as I argued, the schmidentity argument is in fact able to carry this burden. The motivation mentioned before is therefore ill-founded, since semantic internalism cannot fulfill the hopes of the representational approach. This insight, in my opinion, has to deprive semantic internalism of a significant amount of its intuitive appeal, plausibility, and argumentative strength in opposition to semantic externalism, and consequently has to shift the dialectical situation in favor of the referential approach, which quite naturally goes with Millianism and direct reference.

Acknowledgements I would like to thank all discussants at the GAP.9 conference for their valuable contributions. I also wish to express my gratitude especially to Michael Wallner, Thomas Valentin Harb, Gregor Hörzer, Frank Hofmann, Tristan Haze, Christian Piller, and the participants of the PhD reading circle for philosophy at the Université du Luxembourg, who commented on drafts of the present text and/or discussed topics of relevance for this paper with me. Three anonymous referees for Synthese contributed valuable suggestions which, I think, significantly improved the quality and especially readability of the text. Last but not least, special thanks also go to Marian David and Martina Fürst, since this text would never have come into existence without them. Open access funding provided by the University of Luxembourg.

Open Access This article is licensed under a Creative Commons Attribution 4.0 International License, which permits use, sharing, adaptation, distribution and reproduction in any medium or format, as long as you give appropriate credit to the original author(s) and the source, provide a link to the Creative Commons licence, and indicate if changes were made. The images or other third party material in this article are included in the article's Creative Commons licence, unless indicated otherwise in a credit line to the material. If material is not included in the article's Creative Commons licence and your intended use is not permitted by statutory regulation or exceeds the permitted use, you will need to obtain permission directly from the copyright holder. To view a copy of this licence, visit http://creativecommons.org/licenses/by/4.0/.

\footnotetext{
45 For a congenial approach, see Almog (2004).

46 This is not to say that there is no connection between the questions what our linguistic expressions mean and how we represent the world. Still, it needs to be emphasized that these questions come apart, and consequently have to be treated separately.
} 


\section{References}

Almog, J. (2004). The proper form of semantics. In M. Reimer \& A. Bezuidenhout (Eds.), Descriptions and beyond (pp. 390-419). Oxford: Oxford University Press.

Almog, J. (2005). Is a unified description of language-and-thought possible? Journal of Philosophy, 102(10), 493-531.

Bach, K. (1987). Thought and reference. Oxford: Clarendon Press.

Bach, K. (1999). The Myth of conventional implicature. Linguistics and Philosophy, 22(4), 327-366.

Bach, K. (2002). Giorgione was so-called because of his name. Nô̂s, 36(s16), 73-103.

Benfield, D., \& Erwin, E. (1975). Identity, schmidentity—it's not all the same. Philosophical Studies, 27(2), $145-148$.

Burgess, A., \& Sherman, B. (2014). Introduction: A plea for the metaphysics of meaning. In A. Burgess \& B. Sherman (Eds.), Metasemantics: New essays on the foundations of meaning (pp. 1-16). Oxford: Oxford University Press.

Burgess, J. P. (2014). On a derivation of the necessity of identity. Synthese, 191(7), 1567-1585.

Båve, A. (2008). A pragmatic defense of Millianism. Philosophical Studies, 138(2), 271-289.

Caton, C. E. (1976). The idea of Sameness challenges reflection. In M. Schirn (Ed.), Studien zu Frege II. Logik und Sprachphilosophie / Studies on Frege II. Logic and Philosophy of Language (pp. 167-180). Stuttgart-Bad Cannstatt: Frommann-Holzboog.

Deutsch, H., \& Garbacz, P. (2018). Relative identity. In E. N. Zalta (Ed.), The Stanford encyclopedia of philosophy (fall 2018 ed.). Stanford: Metaphysics Research Lab, Stanford University.

Devitt, M. (1981). Donnellan's distinction. Midwest Studies in Philosophy, 6(1), 511-524.

Devitt, M. (2004). The case for referential descriptions. In M. Reimer \& A. Bezuidenhout (Eds.), Descriptions and beyond (pp. 280-305). Oxford: Oxford University Press.

Donnellan, K. S. (1966). Reference and definite descriptions. The Philosophical Review, 75(3), $281-304$.

Fine, K. (1989). The problem of De Re modality. In J. Perry, J. Almog, \& H. K. Wettstein (Eds.), Themes from Kaplan (pp. 197-272). Oxford: Oxford University Press.

Fine, K. (2003). The role of variables. Journal of Philosophy, 100(12), 605-631.

Fine, K. (2007). Semantic relationism. Malden: Blackwell Publishing.

Fodor, J. A. (2008). LOT 2: The language of thought revisited. Oxford: Oxford University Press.

Fraissler, H. (2014). Identität bei Saul Kripke. Oder: Was uns Schmidentität über Identität sagen kann/Saul Kripke on Identity. Or: What Schmidentity can tell us about Identity. Diploma Thesis, Karl-FranzensUniversität Graz, Graz.

Frege, G. (1960). On sense and reference. In M. Black \& P. Geach (Eds.), Translations from the philosophical writings of Gottlob Frege (2nd ed., pp. 56-78). Oxford: Basil Blackwell.

Freitag, W. (2009). Is 'a = a' Apriori? Language and World-Papers of the XXXII international Wittgenstein symposium (pp. 133-135).

Geach, P. T. (1964). Referring expressions again. Analysis, 24(5), 172-175.

Geach, P. T. (1980). Reference and generality: An examination of some medieval and modern theories (3rd ed.). Ithaca: Cornell University Press.

Hawthorne, J., \& Lepore, E. (2011). On words. Journal of Philosophy, 108(9), 447-485.

Haze, T. (2016). On identity statements: In defense of a Sui Generis view. Disputatio, 8(43), 269-293.

Kaplan, D. (1990). Words. Proceedings of the Aristotelian Society, Supplementary Volumes, 64, 93-119.

Kaplan, D. (2011). Words on words. Journal of Philosophy, 108(9), 504-529.

Kripke, S. A. (1980). Naming and necessity. Cambridge: Harvard University Press.

Kripke, S. A. (2011a). Identity and necessity. In Philosophical Troubles. Collected papers (Vol. 1, pp. 1-26). Oxford: Oxford University Press.

Kripke, S. A. (2011b). Presupposition and anaphora: Remarks on the formulation of the projection problem. In Philosophical Troubles. Collected papers (Vol. 1, pp. 351-372). Oxford: Oxford University Press.

Kripke, S. A. (2011c). A puzzle about belief. In Philosophical Troubles. Collected papers (Vol. 1, pp. 125-161). Oxford: Oxford University Press.

Kripke, S. A. (2011d). Speaker's reference and semantic reference. In Philosophical Troubles. Collected papers (Vol. 1, pp. 99-124). Oxford: Oxford University Press.

Kripke, S. A. (2013). Reference and existence: The John Locke lectures. New York: Oxford University Press.

Larson, R. K., \& Ludlow, P. (1993). Interpreted logical forms. Synthese, 95(3), 305-355.

McGinn, C. (2015). Philosophy of language: The classics explained. Cambridge, Mass.: MIT Press. 
Millican, P., \& Over, D. (1990). Content, thoughts, and definite descriptions. Proceedings of the Aristotelian Society, Supplementary Volumes, 64, 167-220.

Morris, T. V. (1984). Understanding identity statements. Aberdeen: Aberdeen University Press.

Muehlmann, R. (1969). Russell and Wittgenstein on identity. The Philosophical Quarterly, 19(76), 221-230.

Nevins, A. \& Vaux, B. (2003). Metalinguistic, shmetalinguistic: The phonology of Shm-Reduplication. In The proceedings of the 39th Chicago Linguistics Society (pp. 702-721).

Onofri, A. (2013). On non-pragmatic Millianism. Philosophical Studies, 166(2), 305-327.

Perry, J. (2015). The cognitive contribution of names. In A. Bianchi (Ed.), On reference (pp. 189-208). Oxford: Oxford University Press.

Petersen, S. (2008). Analysis, schmanalysis. Canadian Journal of Philosophy, 38(2), 289-299.

Ramachandran, M. (1989). Sense and schmidentity. The Philosophical Quarterly, 39(157), 463-471.

Ramachandran, M. (1995). Methodological reflections on two Kripkean strategies. Proceedings of the Aristotelian Society, 95(1), 67-81.

Salmon, N. (1986). Frege's puzzle. Cambridge: MIT Press.

Salmon, N. (1989). How to become a Millian Heir. Noûs, 23(2), 211-220.

Salmon, N. (2005). Existence. In Metaphysics, mathematics, and meaning. Philosophical Papers I (pp. 9-49). Oxford: Oxford University Press.

Salmon, N. (2012). Recurrence. Philosophical Studies, 159(3), 407-441.

Salmon, N. (2018). Cognition and recognition. Intercultural Pragmatics, 15(2), 213-235.

Soames, S. (2012). Two Versions of Millianism. In W. P. Kabasenche, M. O’Rourke, \& M. H. Slater (Eds.), Reference and Referring (pp. 83-118). Cambridge, Mass.: MIT Press.

Soames, S. (2014). Cognitive propositions. In New thinking about propositions (pp. 91-124). Oxford: Oxford University Press.

Speaks, J. (2018). Theories of meaning. In E. N. Zalta (Ed.), The Stanford encyclopedia of philosophy (winter 2018 ed.). Stanford: Metaphysics Research Lab, Stanford University.

Stalnaker, R. C. (1975). Presuppositions. In D. Hockney, W. Harper, \& B. Freed (Eds.), Contemporary research in philosophical logic and linguistic semantics (pp. 31-41). Dordrecht: D. Reidel.

Stalnaker, R. C. (1999a). Pragmatic presuppositions. In Context and content (pp. 47-62). Oxford: Oxford University Press.

Stalnaker, R. C. (1999b). Pragmatics. In Context and content (pp. 31-46). Oxford: Oxford University Press.

Stalnaker, R. C. (2002). Common ground. Linguistics and Philosophy, 25(5-6), 701-721.

Textor, M. (2007). Namen und Identität. In A. Rami \& H. Wansing (Eds.), Referenz und Realität (pp. 237-259). Paderborn: Mentis.

Ullian, J. S. (1961). More on "Grue" and Grue. The Philosophical Review, 70(3), 386-389.

Wettstein, H. (1986). Has semantics rested on a mistake? The Journal of Philosophy, 83(4), 185-209.

Wettstein, H. (1989). Turning the tables on Frege or how is it that "Hesperus is Hesperus" is trivial? Philosophical Perspectives, 3, 317-339.

Wettstein, H. (2004). The magic prism: An essay in the philosophy of language. New York: Oxford University Press.

Wezenberg, H. (2015). The content and nature of thought. A semantic relationist approach to language and the mind. Ph.D. Thesis, Humboldt-Universität zu Berlin, Berlin.

White, R. (1978). Wittgenstein on identity. Proceedings of the Aristotelian Society, 78(1), 157-174.

Williams, C. J. F. (1989). What is identity?. Oxford: Clarendon Press.

Yagisawa, T. (1993). A semantic solution to Frege's puzzle. Philosophical Perspectives, 7, 135-154.

Publisher's Note Springer Nature remains neutral with regard to jurisdictional claims in published maps and institutional affiliations. 